\title{
Droperidol, Its Alpha-Adrenergic Blocking Action on the Aortic Strip and Inhibitory Action on Norepinephrine Uptake of the Adrenergic Terminal of the Left Atrial Strip of Rabbit
}

\author{
Mitsuo Satoh, * Keiji Kaya, $†$ Ikuo Yamanaka, $\ddagger$ Asahiko \\ Kasama* and Mrtsuhiko Yanagisawa \\ *Department of Anesthesiology, Juntendo University School \\ of Medicine, $\uparrow$ Department of Anesthesiology, Tokyo Metropolitan \\ Bokuto Hospital, $₫$ Department of Anesthesiology, St. Marianna \\ University School of Medicine, and $\S$ Department of Pharma- \\ cology, Juntendo University School of Medicine, Tokyo
}

Satoh, M., Kaya, K., Yamanaka, I., Kasama, A. and Yanagisawa, M. Droperidol, Its Alpha-Adrenergic Blocking Action on the Aortic Strip and Inhibitory Action on Norepinephrine Uptake of the Adrenergic Terminal of the Left Atrial Strip of Rabbit. Tohoku J. exp. Med., 1978, 124 (1), 65-72—In aortic strips, the dose-response curves for phenylephrine were obtained before and after addition of droperidol. Droperidol caused a parallel shift of the curves dose-dependently toward the right side and its grade of the shift was greater than caused by phentolamine at the same concentration. In the left atrial strip, the potentiation of contraction by tyramine was markedly depressed by droperidol. In the reserpinized preparation, the effect of tyramine was depressed markedly and there was no norepinephrine fluorescence. After incubation with norepinephrine they were restored to the same level as in non-reserpinized preparations. However, incubation with droperidol before norepinephrine blocked the restoration. It is postulated that droperidol may have both alpha-adrenergic blocking action and inhibitory action on norepinephrine uptake by adrenergic terminals. — droperidol; alphaadrenergic blocking action; norepinephrine uptake; phenylephrine dose-response curve: fluorescent histochemistry

The use of droperidol in clinical anesthesia is stated to confer advantages in cardiovascular stability. However, in the hypovolemic state, it produces severe hypotension. As to the mechanism of its effect there has been controversial opinions. Corssen et al. (1964) and Whitman and Russell (1971) suggested that this was the result of alpha-adrenergic blockade. This explanation has been questioned by Puddy (1971) and Green (1972), who described that droperidol was a nonspecific inhibitor of vasoconstriction rather than a competitive alpha-adrenergic blockade. Recently, unexplained sustained hypertension which occurred during

Received for publication, June 17, 1977.

I Present address: Department of Anesthesiology, Tohoku University School of Medicine.

This paper is presented in commemoration of the 60th anniversary of the First Department of Surgery, Tohoku University School of Medicine. 
thalamonal (mixture of droperidol $2.5 \mathrm{mg}$ and fentanyl $0.05 \mathrm{mg} / \mathrm{ml}$ ) anesthesia was reported (Feingold and Ivankovic 1969; Iwatsuki 1973). But there has been no report that may explain its mechanism.

In order to solve these questions, the present study was concerned with the interaction of droperidol with phenylephrine $(\mathrm{PE})$, norepinephrine (NE), isoproterenol (ISP) and tyramine on the isolated aortic and left atrial strip of rabbit, and furthermore examined the effect of droperidol on the uptake of norepinephrine by adrenergic terminal by means of fluorescent histochemistry.

\section{Methods}

Preparation of aortic and atrial strips. Rabbits, weighing $2.5-3.0 \mathrm{~kg}$, were killed by blowing the head, and the descending aorta and the left atrium were isolated. Spirally cutted aortic strips of $3 \mathrm{~cm}$ in length, as prepared by the procedures as described by Furchgott (1960), were mounted in a cylindrical chamber of $100 \mathrm{ml}$. The bathing solution used was the Krebs-Henseleit solution equilibrated with a gas mixture of $95 \% \mathrm{O}_{2}$ and $5 \% \mathrm{CO}_{2}$ at $37 \mathrm{C}^{\circ}$. After exerting a tension of $3 \mathrm{~g}$ the contraction was recorded isometrically on polygraphs by using a force-displacement transducer (Nihon-Koden). Isolated left atria $(0.5 \times 2.0 \mathrm{~cm})$ were fixed on a pair of stimulating electrodes at one end, and the other end was connected to the force-displacement transducer. Both aortic and atrial preparations were mounted in the same chamber filled with the Krebs-Henseleit solution. Each strip was subjected to a resting tension of $2 \mathrm{~g}$ and its isometrical contractile tension was recorded. The electrical stimulation consisted of rectangular pulses of $5 \mathrm{msec}$ duration, $5-8 \mathrm{~V}$ in strength and $60 \mathrm{~Hz}$ in frequency.

Reserpine treatment and incubation with norepinephrine and droperidol. The intraperitoneal administration of $5 \mathrm{mg} / \mathrm{kg}$ of reserpine was followed by an intraperitoneal injection of $150 \mathrm{mg} / \mathrm{kg}$ of nialamide (MAO inhibitor) $22 \mathrm{hr}$ later. The atrial strips were removed for study $24 \mathrm{hr}$ after reserpine administration.

These reserpinized atria were incubated with $10^{-6} \mathrm{M}$ of $\mathrm{NE}$ or $10^{-7} \mathrm{M}$ of droperidol in the Krebs-Henseleit solution for $15 \mathrm{~min}$ at $37^{\circ} \mathrm{C}$ and then washed out three times with $100 \mathrm{ml}$ of the Krebs-Henseleit solution for study.

Fluorescent histochemistry examination. By means of the technique of Falck et al. (1962), the left atria were prepared for an observation of fluorescence induced by NE. The preparation was observed under a Zeiss fluorescence microscope and photographed on Fuji X-ray film.

\section{Results}

\section{Aortic strips}

The effect of droperidol on tension development induced by $P E\left(10^{-6} \mathrm{M}\right)$, histamine $\left(10^{-6} \mathrm{M}\right)$ or potassium $\left(25 \times 10^{-3} \mathrm{M}\right)$. All the contraction induced by these agents were depressed by droperidol. The PE-induced contraction was reduced by the lowest concentration of droperidol $\left(10^{-8} \mathrm{M}\right)$, but the highest concentration $\left(10^{-5} \mathrm{M}\right)$ of droperidol was required to depress the potassium-induced contraction (Fig. 1).

The effect of droperidol on the dose-response curve of $P E$ and histamine. The dose-response curves for PE were obtained before and after the addition of $10^{-9}$, $10^{-8}$ and $10^{-7} \mathrm{M}$ of droperidol. The curve for histamine was obtained before and after the addition of $10^{-6} \mathrm{M}$ of droperidol. Droperidol produced the parallel shift 


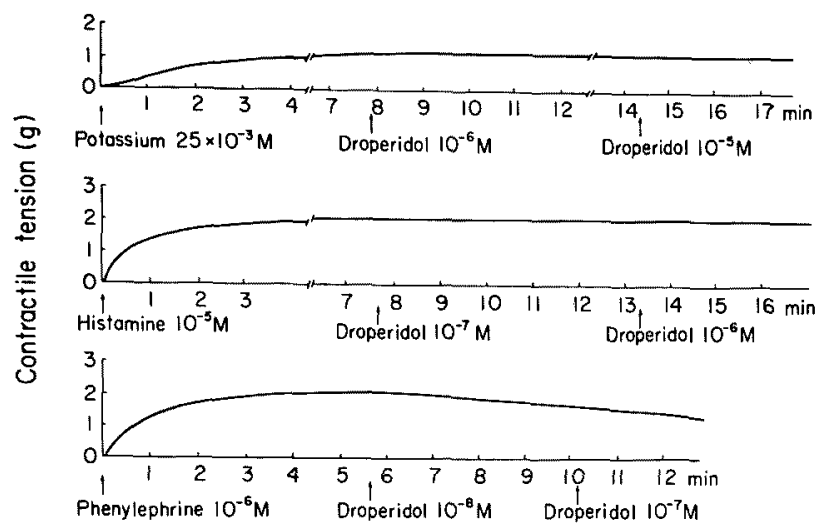

Fig. 1. The effects of droperidol on the isometric contraction of the aortic strip induced by potassium $\left(25 \times 10^{-3} \mathrm{M}\right)$, histamine $\left(10^{-5} \mathrm{M}\right)$ and phenylephrine $\left(10^{-6} \mathrm{M}\right)$.

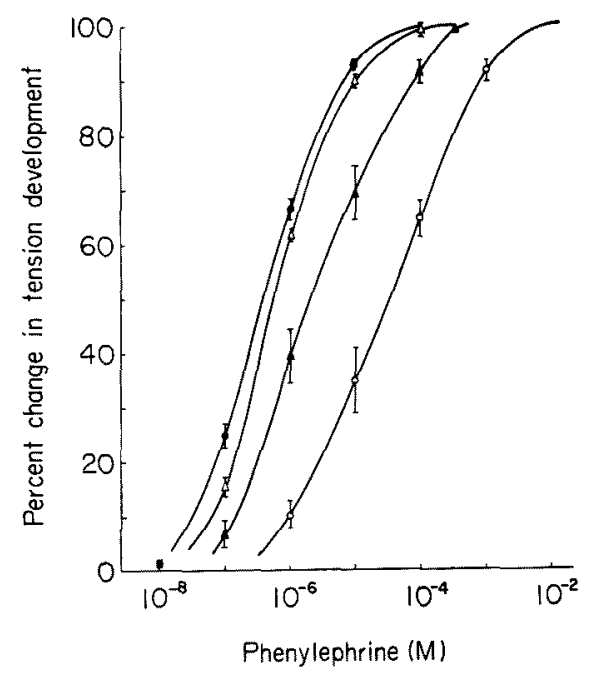

Fig. 2. The effect of droperidol on the phenylephrine dose-response curve. Aortic strips. Each value is given as mean \pm S.D. droperidol $10^{-8} \mathrm{M} ; \Delta-\Delta$, droperidol $10^{-\theta} \mathrm{M}$.

of the $\mathrm{PE}$ dose-response curve to the right side, and its grades were dependent on the concentration of droperidol (Fig. 2). Under the same concentration (10-7 M), the grade of the shift produced by droperidol was greater than that produced by phentolamine (Fig. 3). The histamine dose-response curve was shifted to the right

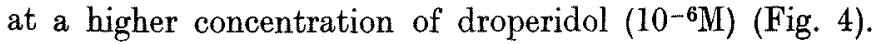

\section{Left atrial strip}

Non-reserpinized preparations. Effect of droperidol on the contractile tension derived by electrical stimuli was studied. There was a slight depression of the contractile tension by a droperidol of $10^{-6} \mathrm{M}$. 


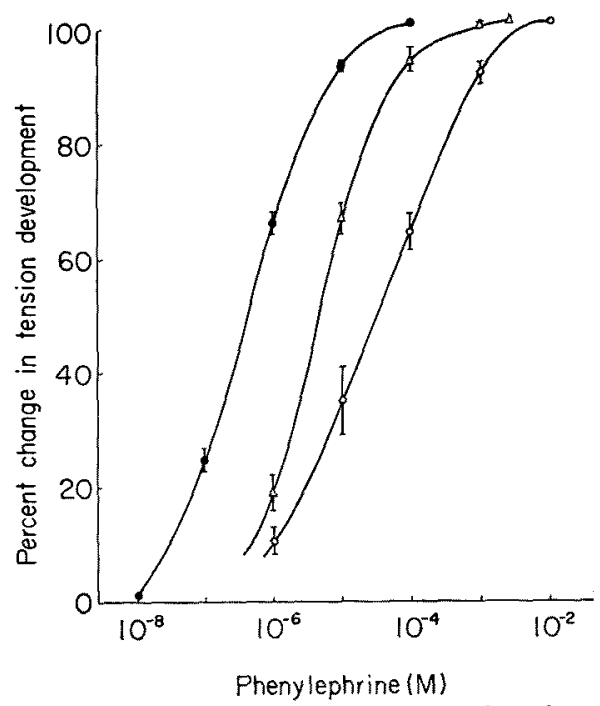

Fig. 3. The effect of droperidol and phentolamine on the phenylephrine dose-response curve. Aortic strips. Each value is given as mean \pm S.D. $-\bullet$, control; $0-0$, droperidol $10^{-7} \mathrm{M} ; \Delta-\Delta$, phentolamine $10^{-7} \mathrm{M}$.

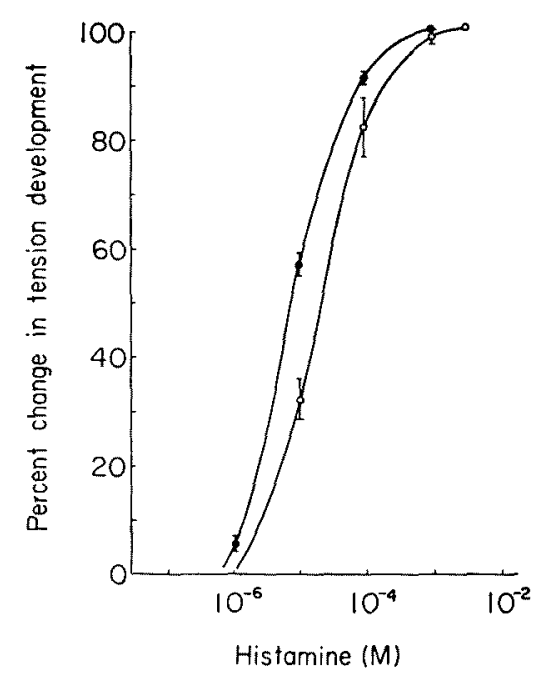

Fig. 4. The effect of droperidol on the histamine dose-response curve. Aortic strips. Each value is given as mean \pm s.D.

$\longrightarrow$, control; o-o, droperidol $10^{-6} \mathrm{M}$.

Effect of droperidol on the potentiation of contractile tension with NE, ISP and tyramine was as follows. By the pretreatment with $10^{-7} \mathrm{M}$ of droperidol, the potentiation with $10^{-5} \mathrm{M}$ of $\mathrm{NE}$ was slightly increased and that with $10^{-7} \mathrm{M}$ of ISP was not changed significantly. On the other hand, the potentiation with tyramine was markedly depressed by the pretreatment with $10^{-7} \mathrm{M}$ of droperidol (Table. 1). 
TABLE 1. Non-reserpinized preparation: The effect of droperidol $\left(10^{-7} M\right)$ on the norepinephrine (NE), isoproterenol (ISP) and tyramine potentiation of the atrial contractile tension

\begin{tabular}{lcc}
\hline & Before droperidol & After droperidol \\
\hline NE $\left(10^{-5} \mathrm{M}\right)$ & $723 \pm 25$ & $766 \pm 56$ \\
ISP $\left(10^{-7} \mathrm{M}\right)$ & $498 \pm 152$ & $495 \pm 170$ \\
Tyramine $\left(10^{-7} \mathrm{M}\right)$ & $352 \pm 72$ & $190 \pm 75$ \\
\hline
\end{tabular}

Each value is given as mean \pm S.D. of percent change in tension development from control.

TABLE 2. Reserpinized preparation: The effect of tyramine on the tension development of the atrium with $\mathrm{NE}\left(10^{-6} \mathrm{M}\right)$ and droperidol $\left(10^{-7} \mathrm{M}\right)$ incubations

\begin{tabular}{lc}
\hline \multicolumn{1}{c}{ Incubation } & Tyramine $\left(10^{-7} \mathrm{M}\right)$ \\
\hline None & $178 \pm 84$ \\
NE & $337 \pm 142$ \\
Droperidol, then NE & $180 \pm 44$ \\
NE, then droperidol & $413 \pm 104$
\end{tabular}

Each value is given as mean \pm S.D. of precent change in tension development from control.

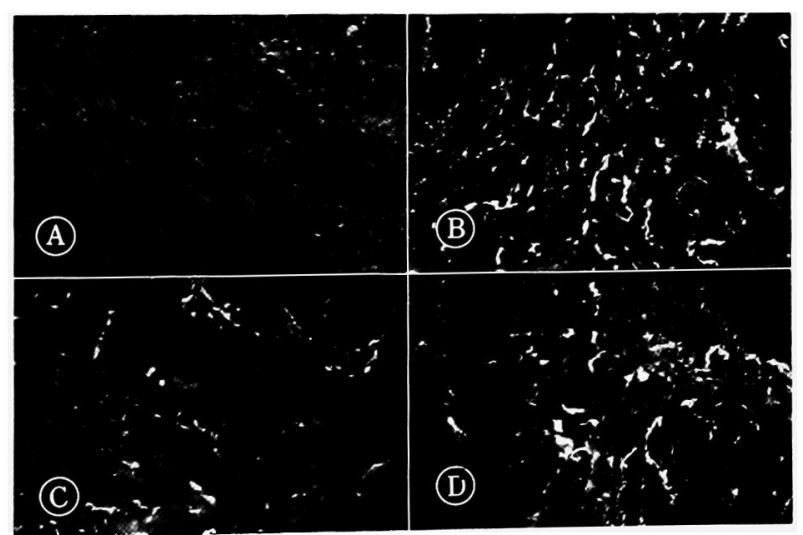

Fig. 5. NE fluorescence in the reserpinized atrium.

A: Control.

B: Preparation after incubation with NE.

C: Preparation after incubation with droperidol, then NE.

D: Preparation after incubation with NE, then droperidol.

Reserpinized preparation. Effect of tyramine before and after incubation with $10^{-6} \mathrm{M}$ of $\mathrm{NE}$ and $10^{-7} \mathrm{M}$ of droperidol was observed. The potentiation of contractile tension with $10^{-7} \mathrm{M}$ of tyramine before the incubation with $\mathrm{NE}$ was markedly reduced as compared with that of non-reserpinized preparations. The incubation with $\mathrm{NE}$ led to restore the tyramine potentiation to the level of the 
non-reserpinized preparation (Table 2). The restoration of tyramine potentiation was not influenced by the incubation with droperidol after with NE. However, the incubation with droperidol before with $\mathrm{NE}$ blocked the restoration completely (Table. 2).

Fluorescent histochemistry. In the reserpinized preparation there was no $\mathrm{NE}$ fluorescence. By the incubation with $\mathrm{NE}$ the intense fluorescence was observed. However, it was diminished again by the incubation with droperidol before with NE (Fig. 5).

\section{Discusston}

Droperidol, a neuroleptic agent, produced hypotension in man (Macdonald et al. 1966) and experimental animals (Yelnosky et al. 1964). Although some papers (Corssen 1964: Whitman and Russell 1971) suggested that this was the result of alpha-adrenergic blocking action, they have not been examined on the isolated preparation basically yet. Puddy (1971) has demonstrated that droperidol blocked vasoconstriction induced by histamine and potassium as well as by NE in the isolated rabbit auricular preparations. Johnstone (1970) and Greene (1972) have shown that droperidol has a local anesthetic action in man and guinea pig. It appears that droperidol has non-specific antagonism to vasoconstriction rather than specific alpha-adrenergic antagonism. However, it is well known that alpha-adrenergic antagonists have also antihistaminic and non-specific inhibitory action under somewhat higher concentration.

In the aortic strip which is most convenient for evaluating the effect of vasoactive agents, the dose-response curve of $\mathrm{PE}$, being regarded as pure alphaadrenergic agonist, was the most sensitive to droperidol and was brought in dosedependent parallel shift to the right side by droperidol (Fig. 2). On the other hand, that of histamine was slightly shifted by $10^{-6} \mathrm{M}$ of droperidol (Fig. 4) and furthermore, potassium contraction was less depressed even at higher concentration of droperidol, such as $10^{-5} \mathrm{M}$ (Fig. 1). Thus it is suggested that droperidol may have a specific alpha-adrenergic blocking action on the aortic strip of rabbit, which is more potent than phentolamine (Fig. 3).

In clinical application, it is apparent that phentolamine is more potent than droperidol in respect of vasodepression, and the sustained hypertension due to droperidol in man was reported (Feingold and Ivenkovic 1969; Iwatsuki 1973). Therefore, droperidol seems to have an excitatory effect on the cardiovascular system in addition to its alpha-adrenergic blocking action.

In the atrial preparation, the pretreatment with droperidol caused no significant change in the potentiation of contraction induced by NE and ISP. On the other hand, it reduced the tyramine potentiation markedly (Table 1). Tyramine is one of the adrenergic agonists, which have an indirect action, being dependent on NE release from the adrenergic terminal. Thus we would propose that the inhibitory effect of droperidol on tyramine potentiation might be attributed to block either the uptake of tyramine into adrenergic terminals, or NE release 
from adrenergic terminals. In the reserpinized preparation, the tyramine effect was depressed markedly because of depletion of $\mathrm{NE}$ in the adrenergic terminals. The incubation with NE led to restoration of essentially normal sensitivity of atria to tyramine. This restoration, however, was completely blocked by the incubation with droperidol before with NE (Table. 2).

The neuronal uptake of tyramine takes place in the same way as that of $\mathrm{NE}$ (Smith 1973). Therefore, droperidol may be able to block the uptake of NE as well as tyramine into the adrenergic terminals. This suggestion was examined directly by means of the method of fluorescent histochemistry. The incubation of reserpinized preparations with NE led to restoration of intense NE fluorescence. But there was only a slight fluorescence in the reserpinized preparation incubated with droperidol before with NE (Fig. 5). The incubation with NE leads to repletion of $\mathrm{NE}$ store not only in the adrenergic terminal, but also in the myocardial cell. However, it is necessary to incubate with somewhat higher concentration of $\mathrm{NE}$ in order to get enough repletion of NE in the myocardial cell, and NE in the myocardial cell is easily diminished after thorough washout, because it is less stable than that in the adrenergic terminal (Avakian and Gillespie 1968). Therefore it seems likely that the restoration of tyramine effect and NE fluorescence in the reserpinized atrium with NE incubation is due to NE taken up not into the myocardium, but into the adrenergic terminal, and droperidol may inhibit NE uptake into the adrenergic terminal.

The adrenergic blocking agents, such as phentolamine, phenoxybenzamine and propranolol, can also inhibit the NE uptake; in the isolated rat heart, concentrations being required to produce $50 \%$ inhibition of NE uptake were $10^{-5}$ to $10^{-6} \mathrm{M}$ (Iversen 1975). They are markedly high as compared with that of droperidol shown in the present data.

Thus it is thought that droperidol has both alpha-adrenergic blocking action and inhibitory action on NE uptake of the adrenergic terminal, which is more potent than other adrenergic blockers. If these results might be applicable to the clinical cases, the NE concentration at the adrenergic receptor would increase by the blocking action of droperidol on NE uptake of the adrenergic terminal, and this phenomenon could counteract the alpha-adrenergic blocking action of droperidol itself and furthermore reveal the activation of beta-adrenergic receptors. This could explain in part the excitatory effect of droperidol on the cardiovascular system, such as hypertension or tachycardia. We used commerical preparation

TABLE 3. The effect of the droperidol solvent on tyramine potentiation of the atrial contraction

\begin{tabular}{ccc}
\hline & $\begin{array}{c}\text { Before treatment } \\
\text { with solvent }\end{array}$ & $\begin{array}{c}\text { Aftre treatment } \\
\text { with solvent }\end{array}$ \\
\hline Tyramine $\left(10^{-7} \mathrm{M}\right)$ & $374 \pm 118$ & $349 \pm 105$ \\
\hline
\end{tabular}

Each value is given as mean \pm S.D. of percent change in tension development from control. 
of droperidol (Droleptan) in the study. Its solvent contains lactic acid, methyl$p$-hydrobenzoate and propyl-p-hydroxybenzonate. The solvent was examined as to whether it affects the potentiating effect of tyramine on atrial contraction or not. As shown in Table 3, the tyramine potentiation was not influenced at all by pretreatment with the solvent.

\section{References}

1) Avakian, O.V. \& Gillespie, L.S. (1968) Uptake of noradrenaline by adrenergic nerves, smosth muscle and connective tissue in isolated perfused arteries and its correlation with the vasoconstrictor response. Brit. J. Pharmacol. Chemother, 32, 168-184.

2) Corssen, G., Domino, E.F. \& Sweet, B.R. (1964) Neuroleptanagesia and anesthesia. Anesth. Analg. Curr. Res., 43, 748-762.

3) Falck, B., Hillarp, N., Thieme, G. \& Trop, A. (1962) Fluorescence of catecholamine and related compounds condensed with formaldehyde. J. Histochem. Cytochem., 10, 348-354.

4) Feingold, A. \& Ivankovic, A. (1969) Sustained hypertension during innovar and innovar- $\mathrm{N}_{2} \mathrm{O}$ anesthesia. Anesthesiology, 31, 476-478.

5) Furchgott, R.F. (1960) In: Methods in Medical Research, edited by H.D. Bruner, Vol. 8, Year Book Publishers, Inc., Chicago, p. 177.

6) Green, M.J. (1972) Some aspects of the pharmacology of droperidol. Brit. J. Anaesth., 44, 1272-1276.

7) Iversen, L.L. (1965) Inhibition of noradrenaline uptake by drugs. J. Pharm. Pharmacol., 17, 62-64.

8) Iwatsuki, K. (1973) Reappraisal of neuroleptanalgesia. Jap. J. Anesth., 22, 625.

9) Johnstone, M. (1970) The pharmacology of drugs used in nouroleptanalgesia. Brit. J. Anaesth., 42, 630 .

10) Macdonald, H.R., Braid, H.P., Stead, B.R., Crawford, D.I. \& Taylor, S.H. (1966) Clinical and circulatory effects of neuroleptanalgesia with dehydrobenzperidol and phenoperidine. Brit. Heart. J., 28, 654-662.

11) Puddy, B.R. (1971) Effects of droperidol on the vasoconstriction produced by noradrenaline, histamine, sympathetic nerve stimulation and potassium ions in the isolated rabbit auricular artery. Brit. J. Anaesth, 43, 441-444.

12) Smith, A.D. (1973) Mechanisms involved in the release of noradrenaline from sympathetic nerves. Brit. med. Bull., 29, 123-129.

13) Whitman, J.G. \& Russell, W.J. (1971) The acute cardiovascular changes and adrenergic blockade by droperidol in man. Brit. J. Anaesth., 43, 581-590.

14) Yelnosky, J., Katz, R. \& Dietric, E.V. (1964) A study of some of the pharmacological actions of droperidol. Toxicol. appl. Pharmacol., 6, 37-47. 